\title{
Development of algorithm for depreciation costs allocation in dynamic input-output industrial enterprise model
}

\author{
Alevtina Keller $^{1}$, and Tatyana Vinogradova ${ }^{1, *}$ \\ ${ }^{1}$ South Ural State University, 454080 Chelyabinsk, Russia
}

\begin{abstract}
The article considers the issue of allocation of depreciation costs in the dynamic inputoutput model of an industrial enterprise. Accounting the depreciation costs in such a model improves the policy of fixed assets management. It is particularly relevant to develop the algorithm for the allocation of depreciation costs in the construction of dynamic input-output model of an industrial enterprise, since such enterprises have a significant amount of fixed assets. Implementation of terms of the adequacy of such an algorithm itself allows: evaluating the appropriateness of investments in fixed assets, studying the final financial results of an industrial enterprise, depending on management decisions in the depreciation policy. It is necessary to note that the model in question for the enterprise is always degenerate. It is caused by the presence of zero rows in the matrix of capital expenditures by lines of structural elements unable to generate fixed assets (part of the service units, households, corporate consumers). The paper presents the algorithm for the allocation of depreciation costs for the model. This algorithm was developed by the authors and served as the basis for further development of the flowchart for subsequent implementation with use of software. The construction of such algorithm and its use for dynamic input-output models of industrial enterprises is actualized by international acceptance of the effectiveness of the use of input-output models for national and regional economic systems. This is what allows us to consider that the solutions discussed in the article are of interest to economists of various industrial enterprises.
\end{abstract}

\section{Introduction}

First pointed to the possibility of building an inputoutput model of the enterprise by the founder of the balance method - W.W. Leontief at work [1]. Building of the input-output model of the enterprise became possible by: a) accumulation of theoretical and practical basis for the study of the models of macro and middle levels, both in Russia and abroad; b) the development of mathematical methods that allow solving degenerate input-output models in Russian schools (including in the Chelyabinsk school: G.A. Sviridyuk [2, 3], S.V. Brychev [4], A.V. Keller [5-7] and etc.)

The common form of the dynamic input-output model of an industrial enterprise is represented by the following equation:

$$
x(t)=A x(t)+B \dot{x}(t)+f(t),
$$

where: $A, B$ are square matrices of size $\mathrm{n} ; A$ - matrix of specific direct costs; $B$ - matrix of specific capital expenditures; $X(t)$ is the vector of gross output; $f(t)$ is a vector of final consumption $[8,9]$.

At the enterprise level, the dynamic input-output model will always be degenerate, because in the matrix $B$ there will always be zero rows $(\operatorname{det} B=0)$ on such structural elements of the model as households and corporate consumers.

Using a degenerate dynamic input-output model (DDIOM) for an industrial enterprise will allow, based on the analysis of economic interrelations between the structural units of the company, to plan the dynamics of the growth of gross output of products for the future, including, taking into account investments in fixed assets.

When building the DDIOM for an industrial enterprise the actual issue is the inclusion of depreciation costs in the structural elements of the model. Today is not exist the methodology and algorithm for allocating such costs in the model for an industrial enterprise (the conclusion is made based on the information known to the authors). The purpose of this paper is to construct an algorithm for the allocation of depreciation costs in the DDIOM. Let's note, that an adequate allocation of depreciation costs in the model will allow to implement a competent policy of management of fixed assets. This is relevant for industrial enterprises.

\section{Degenerate dynamic input-output model of enterprise and the method of its construction}

The study of the construction of balance models for the enterprise is carried out in the works of the following authors: D.V. Ruzakov and P.T. Voronkov [10], P.I. Kuzmin [11], M.I. Letavin and A.A. Banin [12] and others. These researchers combine a unified approach to determining the structural elements of the model, into which they include only the production units, which leads to the construction of static or non-degenerate dynamic input-output models. In addition, in these works, the features of constructing such models are

\footnotetext{
Corresponding author: sh.t.a_90@mail.ru
} 
considered only for specific list of companies of a particular type of activity. In our opinion, the use of such an approach to constructing a model with industry specificity limits its application and reduces the degree of adequacy of mathematical modeling of the company's economic activity. The noted limitation allows to eliminate the construction of the DDIOM by the author's method (A.V. Keller and T.A. Vinogradova). In detail this method is presented in [13].

In the construction of the DDIOM of an industrial enterprise to include following structural elements are to be singled out: a) production units; b) service units; c) for the purposes of accounting for the distribution of net profit, as well as changes in the company's own capital, additional conditional units are «allocated equity capital»; d) external consumers of the company's final products: households (in the form of labor of the company's personnel) and corporate consumers (counterparties). Such a combination of structural elements of the model will allow, on the one hand, to take into account the company's economic relations like an input-output model of the country's economy taking into account export and import, and on the other, opens up new possibilities for researching the economic activity of the enterprise.

Note that TA. Vinogradova developed the algorithm of the program, which will automatically build the matrix that is part of the DDIOM on the basis of the accounting data of the industrial enterprise. This algorithm is presented in [14].

In the Russian chart of accounts only such records of depreciation costs are used, such as «02» (fixed assets) and «05» (intangible assets) [15]. At the same time, the purposes of investment of fixed assets or intangible assets may be different, and the economic effect of putting assets into operation in an industrial enterprise may be different. Thus, for the purpose of increasing the effectiveness of managerial decisions made as a result of the use of the DDIOM, it is necessary to take into account the particularity and specificity of the policy of managing of assets. In this connection, the task is to develop methods and, on their basis, algorithms for distributing the depreciation costs of industrial enterprises, which would take into account: the objectives of investment in fixed assets (including their location); the presence of an economic effect from putting into operation (in the form of an increase in $\mathrm{X}$ ); level of significance of the fixed asset (when making managerial decisions).

\section{Methods and algorithm of allocation of depreciation costs in the DDIOM of an industrial enterprise}

Depreciation costs are inherent costs of the enterprise, with the help of which it becomes possible to transfer the amount of investments into non-current assets for the purchase of fixed assets and intangible assets in parts by the cost of finished products [16].

The essence of the author's approach to the allocation of such costs in DDIOM is as follows: a) it is necessary to allocate two groups of fixed assets (NCA) of the enterprise, depending on the presence or absence of growth in gross output when putting it into operation. So, for example, the purchase of a fixed asset to replace of withdrawing asset can only ensure that the output of finished goods is maintained at the same level. Accordingly, such costs in the future should be included in the matrix of direct costs. If the commissioning of the NCA resulted in a growth of a gross output, then the depreciation costs of it are allocated in the capital expenditures matrix.

b) in the matrices $A$ and $B$ themselves, depreciation costs are proposed to allocate on the main diagonal $(i=$ $j$ ), depending on the $i$-th units $(i=\overline{1, n})$, where the NCA will be put into operation.

The algorithm for allocating depreciation costs in the model consists of four stages.

1st stage - Distribution of depreciation costs for the base period - on the first date of the reporting period (for example, 01/01/2016):

1.1. For each NCA it is necessary to determine:

- the presence of an increase in $X$ in the $j$-th units due to the commissioning of the NCA in the $i$-th units. Further, for the sake of clarity of the representation of this dependence, we introduce the indicator ER. And for such an algorithm, if there is no increase in gross output, then $E R=0$, and $E R=1$ otherwise.

- amount of depreciation costs $\left(\mathrm{DC}_{\mathrm{p}}, \mathrm{p}_{\mathrm{i}}=\overline{1, \mathrm{~b}_{i}}\right)$ for the base period for each NCA;

- location of the NCA ( $i$-th unit).

1.2. A group of significant NCAs is determined.

The degree of significance $(S)$ of assets is determined by the company independently and is prescribed in its accounting policy. The indicator $S$ is characterized by the degree of influence on the user decisions of owners, founders, shareholders and other interested parties. By analogy with the indicator $E R$, the value of the indicator $S=1$ means that the NCA is recognized as significant, and $S=0$ for otherwise.

1.3. For each NCA, which has the values of $E R=1$ and $S=1$, it is also determined:

- indicator $G_{u}$ (the share of gross output growth for the entire period of its useful life in percentages, where $u$ is the ordinal number of years of useful life of the NCA).

After that, indicator $I_{d c} O$ is calculated (the index of accounting for the distribution of depreciation cost by years of useful life for the base period using the formula:

$$
I_{d c} 0=\frac{G_{u}}{100}
$$

- indicator $E R J$ (describes the share of the increase in gross output in the $j$-th units due to the commissioning of the NCA in the $i$-th unit, at that $i \neq j$ ).

1.4. Based on the $E R$ indicator, the total depreciation cost values for each NCA are distributed between the types of cost (direct and capital) according to the following scheme: if $\mathrm{ER}=0$, then such costs are referred to direct, if $\mathrm{ER}=1$, to capital. 
With respect to the NCAs with indicators $S=1, E R=$ 1 and a disproportionate coefficient $G_{u}$ distribution of depreciation costs on them in the accounting period occurs depending on the share of growth in gross output for a given period. For all other NCAs, the actual amount of accrued depreciation is used for calculations.

In the repeated construction of the model, the implementation of point 1.4 is necessary only in case of re-qualification from direct costs to capital type and otherwise.

2nd stage - Correction of depreciation values for NCAs, which are registered with the company on January 1 of the current year.

2.1. Based on the results of the annual revaluation of non-current assets, it is necessary to determine:

- list of NCAs for which the useful life was changed;

- the amount of the residual value for them;

- the amount of increase or decrease in the amount of planned depreciation costs;

- planned values of $E R$ for all NCAs, depreciation of which were related to capital expenditures.

2.2. Based on the data from point 2.1., it is necessary to:

- change in depreciation values (for the reporting period) with respect to increasing or decreasing its amounts as of the end of the base period for each type of cost;

- analyze the need to reallocate amounts of depreciation between two types of cost. If for some NCA the economic effect became zero $(E R=0)$, then depreciation on it in the planned period will be a reallocated into direct costs and otherwise to capital expenditures (for $E R=1$ ).

3rd stage - Allocation of depreciation costs for new NCAs in the reporting period.

3.1. Based on the planned budget investment in noncurrent assets for the reporting period is determined: the quantity of the NCAs that are planned to be recorded, their useful life; the future location; the amount of annual depreciation; the value of the ER.

3.2. The group of acquired NCAs is determined, for which $\mathrm{ERG}=1$.

3.3. For significant NCAs, that having the value of $E R=1$, the following indicators are additionally determined: $G_{u}$ and $E R J$ (see 1.3).

3.4. The distribution of depreciation costs for new NCAs between the types of costs is carried out (similar to point 1.4.).

4th stage - Final allocation of depreciation costs in the model for the reporting period.

4.1 At this stage, the total amount of depreciation costs is finally allocated among the matrixes of the model based on the data of the previous stages. Depreciation, referred to direct costs, is allocated in the matrix of direct costs along the main diagonal. Similarly, the costs are allocated in the capital expenditures matrix.

4.2. Exclusion from the rules of point 4.1: if there are significant NCAs in the company for which $E R=1$ and $E R J=1$, changes are made to the order of allocation of costs. For such assets, it is necessary to analyze the presence in the matrix of direct costs of the relationships between these units. In the case when there are no such interrelations, the depreciation costs for them will be taken into account on the $i$-th line depending on the future location of the asset, on $j$-th line, depending on the units in which the growth of gross output is expected.

In the first construction of the DDIOM, the sequence of the stages of matrices compilation to concerning of depreciation costs: $1.1 \rightarrow 1.2 \rightarrow 1.3 \rightarrow 4.1 \rightarrow 4.2$. For this process, TA. Vinogradova developed a flowchart (Fig. 1).

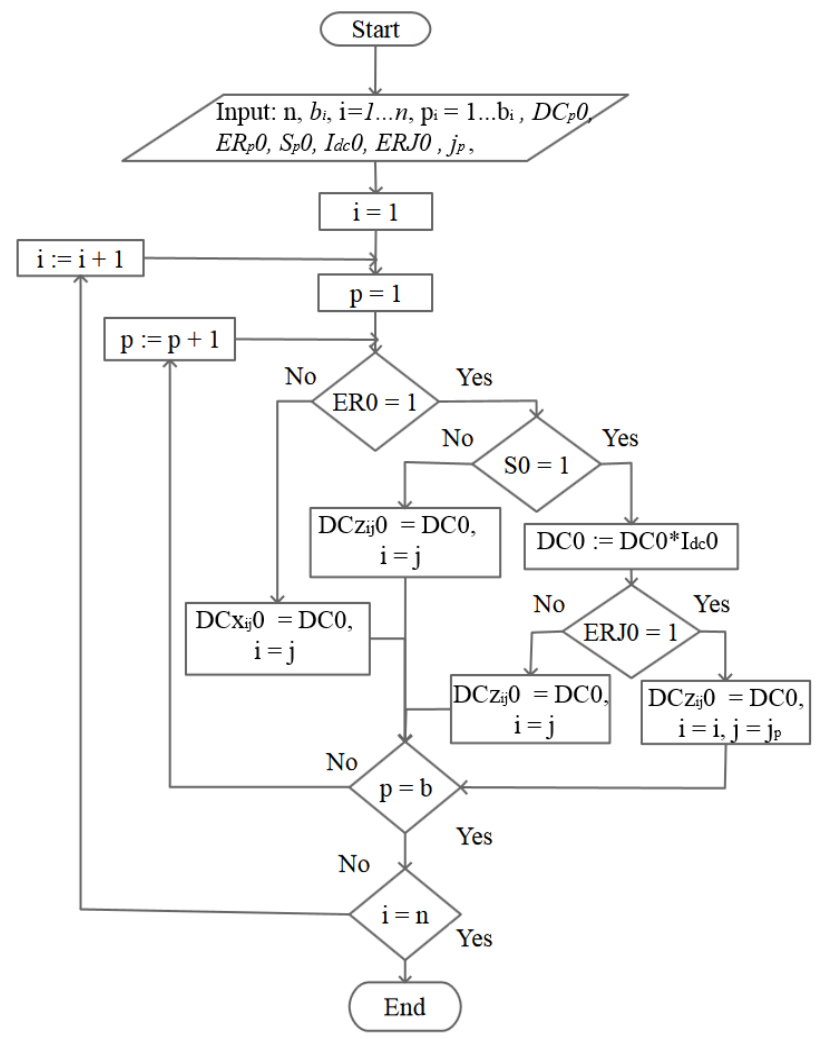

Fig. 1. Flowchart of the allocation of depreciation costs in the construction of the model for the base period.

In repeated the model for subsequent time periods, all the above steps are performed in strict sequence (Fig. 2).

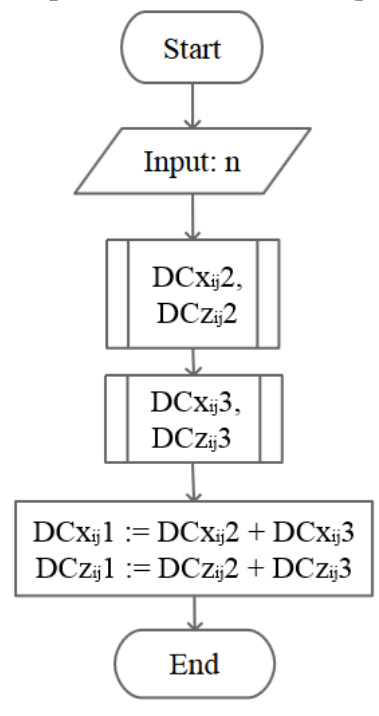

Fig. 2. Flowchart of the allocation of depreciation costs in the construction of the model for the reporting period. 
Calculation $D C x_{i j} 2$ and $D C z_{i j} 2$ is carried out in a similar way to the flowchart (Fig. 1), when the corresponding indices change 0 to 2 . The matrices $D C x_{i j} 3$ and $D C z_{i j} 3$ are compiled to the following flowchart (Fig. 3).

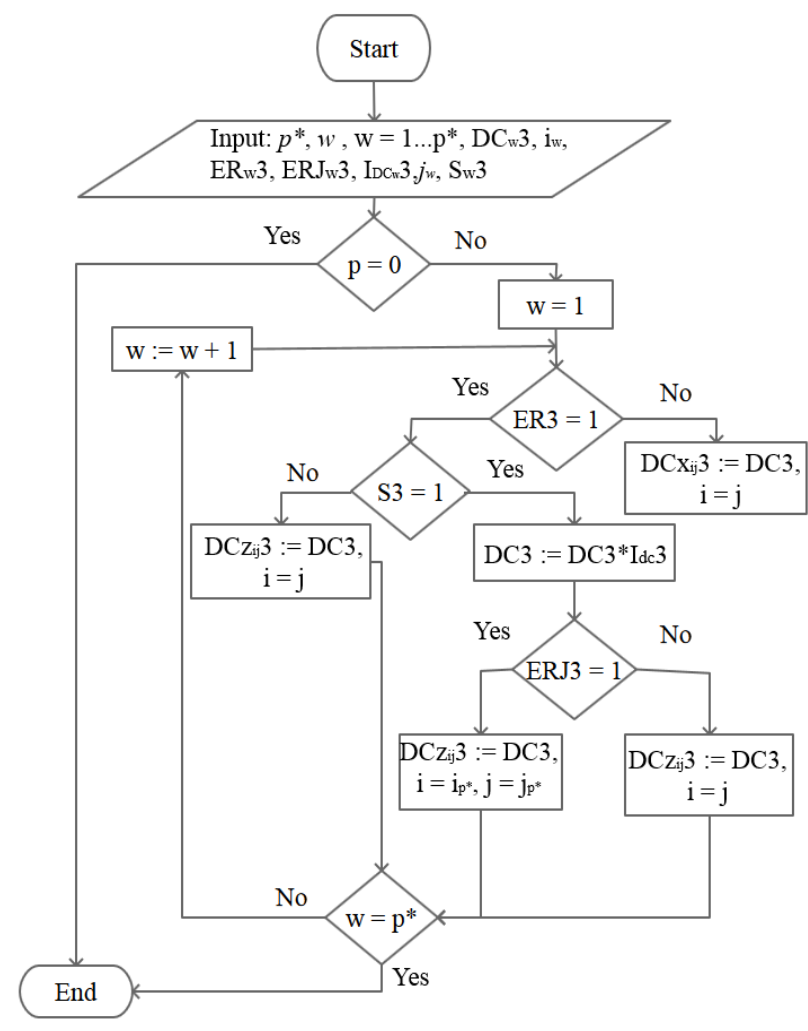

Fig. 3. Allocation of depreciation costs for news NCA.

Let's explain some abbreviations in flowcharts:

- $b_{i}$ is the NCAs quantity for each $i$-th structural element of the model, $i=1 \ldots n$;

$-j_{p}$ is the number of the column in the location of depreciation costs for those NCA for which $S$ and $E R=$ 1

- $p^{*}$ is the number of newly acquired NCA that are registered in the reporting period.

\section{Advantages of using the proposed method}

The use of the author's algorithm creates the possibility of a systematic approach to the management of NCAs of an industrial enterprise.

In the scientific literature, the issue of evaluating the effectiveness of the policy of NCAs management is given to great attention. It is studied in [17, 18, etc.]. In this area, a large number of issues are considered. Describe some of them.

1. Evaluation and validity of the feasibility of investment in the NCAs. This question was considered in $[19,20$, etc. $]$.

These authors have similar methods for evaluating the feasibility of investing in the assets. They are based on the assessment of the resulting economic effect by calculating indicators by the payback period of investments, their profitability, the yield index, the calculation of return on assets, and so on. In these methods, the conclusions are based only on generalized parameters, data and representations on the volume of the production capacity of new equipment (or other NCAs), the amount of costs, the estimated income, taking into account the discount rate. At the same time, the whole set of processes occurring in the company and the structural interrelations between the divisions is not taken into account.

The proposed DDIOM for an industrial enterprise will allow to assess the impact of a change in the structure of NCAs on the value of gross output of all structural elements of the model. Thus, this makes it possible to assess the feasibility of investments for the purchase, renovation, etc. NCAs.

Also, within the framework of standard methods for assessing the feasibility of investments in the NCAs and the need for them, it is not possible to determine the need (and volume) of additional investments in other interrelated units of the company. This is especially relevant when assessing the need for additional investments in servicing units. This problem is solved using the model developed by the authors.

2. The effects of the NCAs revaluation, the extension of useful life on the financial result of the enterprise. These issues relate to such a subsection of the management of the NCAs as an amortization policy [21]. The question is presented in detail in [22, 23, 24, etc.]. When using the proposed DDIOM and the methodology for allocating depreciation costs, it becomes possible to assess such influence.

\section{Conclusion}

In this paper, the algorithm is proposed for the allocation of depreciation costs in the DDIOM of an industrial enterprise. Briefly list the conclusion:

- the authors present the essence of the methodology of allocation of depreciation costs and the algorithm on its basis in the model of an industrial enterprise;

- the algorithm of allocation of depreciation costs, consisting of four stages, is considered in detail;

- a sequence of actions is indicated at the first construction of the model and its compilation for subsequent time periods;

- for each the sequence are presented flowchart of the algorithm for calculating auxiliary matrices for an accounting of the depreciation cost in the model.

The proposed methodology and algorithm for allocation of depreciation costs in the DDIOM of an industrial enterprise is aimed at developing an inputoutput method at the micro level. The use of the methodology will make it possible to increase the effectiveness of making managerial decisions in the implementation of the policy of managing NCA in an industrial enterprise.

The work was supported by Act 211 Government of the Russian Federation, contract № 02.A03.21.0011. 


\section{References}

1. W.W. Leontief, The Structure of the American Economy (Oxford Univesity Press, 1941)

2. G.A. Sviridyuk, S.V. Brychev, JVMMF, 11 (2003)

3. G.A. Sviridyuk, S.V. Brychev, News of HEE: Math, 8 (2003)

4. S.V. Brychev, A study of the mathematical model of the economy of the municipal economy of small towns, 112 (2002)

5. A.V. Keller, Herald of SUSU, 4 (2011)

6. A.V. Keller, Journal of CEM, 2 (2015)

7. A.V. Keller, Numerical study of optimal control problems for Leontief type models: the thesis, 249 (2011)

8. A.G. Granberg, Dynamic models of the national economy (Economics, 1985)

9. N.I. Veduta, Socially Efficient Economy, 254 (1999)

10. P.T. Voronkov, D.V. Ruzakov, Herald of MSU, 4 (2001)

11. P.I. Kuzmin, Herald of ASU. Economy, 2 (2002)

12. A.A. Banin, M.I. Letavin, EMM, 4 (2002)
13. A.V. Keller, T.A. Shishkina, Herald of SUSU, 3(7) (2013)

14. A.V. Keller, T.A. Shishkina, Modern economy: problems and solutions, 9 (2014)

15. D. Volkova, Chart of accounts of financial and economic activity of the enterprise, 122 (2015)

16. A.A. Slobodnyak, I.O. Tsizman, O.A. Prein, Accounting and economic analysis of fixed assets in organizations and institutions, 362 (2014)

17. A.P. Kopteva, RE, 10 (2011)

18. V.A. Fursov, A.A. Solomatina, KANT, 3 (2012)

19. M.E. Grebneva, V.I. Kosik, The role of economic analysis in developing the policy of management of non-current assets, 2 (2016)

20. T.M. Vasilkova, Herald of the MSUM, 5 (2008)

21. E.V. Smolentsev, Depreciation policy as a stage of asset management, 4 (2014)

22. K.V. Gulpenko, PME, 4 (2009)

23. M.L. Pustovalova, Effect of revaluation of fixed assets on return on equity, EB, 1 (2016)

24. I.O. Yursova, I.O. Yakubova, S.M. Baysangurova, IPE, 8 (2011) 